\title{
PÁRAMO, MARÍA LUISA (2017) El carnaval de las coplas, un arte de Cádiz. Madrid: Izana, 514 pp.
}

\section{Estrella Fernández Jiménez \\ Universidad de Cádiz}

Esta obra es una prueba de la relevancia académica que está recobrando el carnaval de Cádiz, no solo desde la perspectiva histórica y social, las cuales han sido, y siguen siendo prolíferas en la investigación sobre este fenómeno, sino desde las vertientes más comunicacionales y antropológicas. Deviene de una tesis doctoral, luego aúna la rigurosidad científica y contrastada de un trabajo académico con el lenguaje divulgativo de una publicación. Es un análisis desde la distancia a la par que un trabajo de campo, entendida "distancia" como que la autora (nacida en La Solana, Ciudad Real, y naturalizada en Madrid) no es escritora de coplas, pero sí deja patente que se trata de un estudio de campo, de participación en el carnaval como espectadora en directo de las actuaciones. El trabajo se divide en cinco amplios capítulos. Cada capítulo está dividido en múltiples apartados y subapartados ya que los capítulos responden a aspectos más generales como "Conceptos previos", "La situación de comunicación", "La producción", "El producto" y "La transmisión". Ser tan generales hace que necesariamente tengan que dividirse en temas más concretos, tarea ardua ya que los aspectos carnavalescos siempre están interconectados y nada funciona de manera aislada. Se percibe un gran esfuerzo por describir las normas de algo que no quiere tenerlas ni aspira a ser descrito.

Desde el principio la autora expone las intenciones de la obra; de todo lo que abarca el carnaval de Cádiz, ella se centra en las coplas, o como ella denomina, en el "carnaval de las coplas”. 
En "Conceptos previos" encontramos todos las nociones necesarias para abordar el carnaval de Cádiz, como son cultura y fiesta, así como un recorrido histórico en el que explica todos los cambios sufridos (censura, cambio de fecha, reglamentos) que han ido modelando el carnaval que puede verse en la actualidad. En este primer capítulo ya plasma que "La palabra es el elemento central de la fiesta gaditana" (pág. 55), tema que vertebra toda la obra.

En el segundo capítulo, "La situación de comunicación", observamos una descripción detallada de cómo se mueve -literalmente- el carnaval de Cádiz por las calles. La autora hace las funciones casi de reportera al transportar al lector a la situación narrada, como por ejemplo esta:

"Una de las situaciones que esperan con interés los aficionados en un carrusel de coros es la coincidencia en un cruce de calle, por ejemplo, de dos bateas que siguen itinerarios distintos, porque en esos casos es frecuente que cada uno de los coros interprete una copla e invite al otro a hacer lo mismo de manera alternativa, dándose así una especie de porfía que busca la emoción, un mano a mano entre las dos agrupaciones para ser la más aclamada por el público presente" (pág. 105).

Tanto en este capítulo como en el anterior y sucesivos, aparece la transcripción de las coplas para ejemplificar y corroborar lo que se está tratando, así como llamadas a pie de página para explicar expresiones y palabras habituales en Cádiz y en el carnaval, pero desconocidas en muchas ocasiones para el resto de personas que puedan enfrentarse a esta obra, ubicando así mejor al lector. Asimismo, describe el funcionamiento organizativo del COAC narrando las evoluciones sufridas hasta la actualidad.

Ya en el capítulo tercero, "La producción", entra de lleno a explicar las modalidades de agrupaciones y sus modos de transmisión de las coplas. La descripción de las agrupaciones oficiales, las concursantes, es una tarea compleja pero posible de alcanzar ya que se circunscriben al reglamento y a normas para concursar: número de componentes, duración de las actuaciones, número de coplas, etc. Mayor dificultad en la descripción y clasificación entrañan las agrupaciones callejeras; como dice la autora de la obra, "El carnaval ilegal, por su libertad y ausencia de normas, es experimentación e innovación continua $\mathrm{y}$, si hubiera podido acercarme a una clasificación de las agrupaciones, seguramente ya no sería válida en cuanto hubieran pasado dos Carnavales como máximo" (pág. 166). Aun así, a lo largo de unas 30 páginas hace una descripción y explicación de dichas agrupaciones, las cuales son las grandes desconocidas para las personas que únicamente conocen el carnaval de Cádiz a través del Concurso de Agrupaciones Carnavalescas, y en este libro se encuentran muchas de las respuestas a preguntas como quiénes las componen, por qué, cómo se organizan, qué ritmos creativos siguen, si sacan algún beneficio económico, qué presencia tienen las mujeres en estas agrupaciones, etc. 
El capítulo cuarto, "El producto", trata sobre uno de los aspectos que más complicado resulta para las personas que comienzan a adentrarse en el carnaval, ya sea como aficionado o como investigador, que es saber distinguir la música y modalidad de coplas. Desglosa y desarrolla en qué consisten la presentación, los tangos, los pasodobles, los cuplés, los estribillos, las parodias, los romances o romanceros, las canciones, los popurrís y los temas libres. Cada explicación va acompañada con varias transcripciones, matizando así las diferencias entre un pasodoble de chirigota y un pasodoble de comparsa, por ejemplo. En el libro podemos encontrar coplas que van desde los años sesenta hasta prácticamente la actualidad.

Pese a desarrollar ampliamente todos y cada uno de los aspectos del carnaval de Cádiz, también en la redacción va dando claves concretas, a modo de resumen o ideas clave, que, aunque no aparezcan resaltadas visualmente en el texto, sí ayudan a centrar al lector, como puede ser: "No hay agrupación carnavalesca si no hay tipo y cuplé; todo lo demás es prescindible" (pág. 278) o "El romance o romancero viene a ser, por tanto, un monólogo paródico, teatral y versificado" (pág. 330). El aficionado sabe a la perfección a qué se está refiriendo con estas afirmaciones. Seguidamente profundiza también en la temática de las coplas, haciendo especial hincapié en los piropos que se dicen, cantan, en el carnaval como uno de los temas más genuinos del carnaval de las coplas. También precisa la importancia del habla de Cádiz y el humor como componentes fundamentales a tener en cuenta para la escritura de las coplas; ironía y eufemismos son capitales en esta tarea.

En el quinto capítulo, "La transmisión", se detiene en la especial comunicación que se establece entre intérpretes y público; precisa que tiene características teatrales y propias de conciertos, pero no es ni lo uno ni lo otro. Analiza las actitudes que tanto el público como los que actúan han de tener para el éxito comunicativo de las coplas. "El carnaval de las coplas es una manifestación comunicativa oral, pero no natural, no espontánea, ya que requiere una manipulación consciente de la lengua y una gran elaboración para conseguir los fines que se propone, entre otros, cumplir una función estética y lúdica" (pág. 471). Muestra así cómo, gracias a la tradición, tanto emisores como receptores entran en una dinámica en la que la comunicación fluye de manera natural y efectiva, lo que ella llama "acuerdo general de la comunicación carnavalesca".

La obra se cierra con un apartado a modo de conclusiones llamado "El género del carnaval de las coplas", donde Páramo argumenta por qué ella considera el carnaval como una modalidad de teatro específica.

Este libro, pese a su gran extensión, al estar bien delimitados los capítulos, apartados y subapartados, permite encontrar de manera precisa los temas que puedan resultar interesantes al lector sin necesidad de leerlo de manera lineal. Es reseñable el intento de 
ordenación del tema que se trata, cuando lo más destacado del carnaval es su aspiración a ser caótico, a ponerlo todo del revés.

Está escrito en primera persona, pero podríamos decir que se trata de una obra polifónica ya que, mediante la transcripción de entrevistas a personas de relevancia en el carnaval de Cádiz, cede la palabra a múltiples protagonistas, autores de las coplas en su mayoría, mostrando con esto varios puntos de vista sobre los temas tratados.

Es una obra práctica para la consulta académica y a la vez accesible para los aficionados que quieran profundizar o ver desde otra perspectiva el arte de las coplas del carnaval de Cádiz. 